\title{
Short communication: Effects of analgesic use postcalving on cow welfare and production
}

\author{
G. Stilwell, ${ }^{\star 1}$ H. Schubert, $†$ and D. M. Broom $†$ \\ *Centro de Investigação Interdisciplinar em Sanidade Animal, Faculdade de Medicina Veterinária, UL. Alto da Ajuda, $1300-477$ Lisboa, Portugal \\ †Centre for Animal Welfare and Anthrozoology, Department of Veterinary Medicine, University of Cambridge, Madingley Road, Cambridge, \\ CB3 OES, United Kingdom
}

\section{ABSTRACT}

The aim of this study was to assess the welfare and production of cows given an analgesic drug (carprofen, $1.4 \mathrm{mg} / \mathrm{kg}$ i.v.) within $6 \mathrm{~h}$ after calving. The study was performed in a dairy farm with approximately 1,000 milking cows. Behavior, clinical indices, and production data (milk yield and fertility) of cows treated with carprofen $(\mathrm{n}=19)$ or a placebo $(\mathrm{n}=20)$ were compared. Additionally, differences related to parity (primiparous vs. multiparous) were analyzed. No significant differences were observed in the time of placental expulsion or incidence of clinical disease over the 3 d postpartum, but more animals from the analgesia group were observed eating during the first hours after calving. For unassisted calvings, the rectal temperature $24 \mathrm{~h}$ postpartum was lower in the cows given analgesic. Total lactation yields at $305 \mathrm{~d}$ in milk were higher in the primiparous cows treated with carprofen. Fewer cows were pregnant at $220 \mathrm{~d}$ postpartum in the treated group as the use of carprofen increased the time from calving to conception. This study suggests that pain management after parturition leads to earlier feed intake after calving and that this may lead to higher milk yield in first-lactation animals.

Key words: calving, pain, analgesia, welfare

\section{Short Communication}

Providing analgesia to the postpartum cow is not a common intervention following an unassisted calving, but may be used following dystocia and is commonly used following a cesarean (Huxley and Whay, 2006). Recent literature review shows that pain management after calving is probably underused and that further research on the use of nonsteroidal antiinflammatory drugs in the postcalving cow is required (Laven et al., 2012).

Received June 4, 2013.

Accepted October 10, 2013.

${ }^{1}$ Corresponding author: stilwell@fmv.utl.pt
Behavior, clinical, and production measures may all be used to indicate pain (Whay et al., 2003; Broom and Fraser, 2007). Pain management after calving may be economically beneficial as a cow that has a better appetite after calving is likely to produce more milk. Inflammation and pain are expected to be more common and severe in primiparous animals because of smaller pelvis area, slower calving, and incomplete vulva dilatation (Mee, 2004).

Research has been conducted on pain in cattle during certain procedures, such as castration and dehorning, and the beneficial effects of using analgesia for such procedures have been demonstrated (Milligan et al., 2004; Pang et al., 2006; Stilwell et al., 2008), but very few published studies have looked at analgesia after calving. Carprofen is an appropriate analgesic for painful procedures in cattle (Stilwell et al., 2008).

In a commercial dairy unit of approximately 1,000 Holstein milking cows in the Ribatejo region of Portugal, parturient cows were housed in a straw-yard, which they entered approximately $3 \mathrm{wk}$ before expected parturition date. Food was distributed once per day in the form of a TMR. Food and water were always available.

During 1 mo, all 39 cows and heifers that calved were observed for as much of stage 2 of parturition as possible and for $8.8 \pm 1.1 \mathrm{~h}$ (no difference between groups) after this stage was completed. There were no caesareans or complicated dystocia and all calves were born alive. Following parturition, each cow was allocated alternatively to either the analgesia group or the control group. Those in the analgesia group $(\mathrm{n}=$ 19) were given carprofen (Rimadyl, $50 \mathrm{mg} / \mathrm{mL}$; Pfizer Animal Health, Dundee, UK) at a dose of $1.4 \mathrm{mg} / \mathrm{kg}$ i.v. immediately after parturition. Those in the control group $(\mathrm{n}=20)$ did not receive any analgesia.

Observations were made live by the same person from the corridor between the maternity pens to minimize disturbance. The time spent attending the calf, eating or drinking, and pain-related behaviors, such as proportion of time spent standing or lying, the amount of time the whites of their eyes were visible, ear position, teeth grinding, kicking the abdomen, and vocalizing 
Table 1. Behavioral data from the postpartum observation period

\begin{tabular}{|c|c|c|}
\hline \multirow[b]{2}{*}{ Behavior } & \multicolumn{2}{|c|}{ Treatment } \\
\hline & Analgesia & Control \\
\hline Number of position changes & 1.4 & 1.6 \\
\hline Proportion of time standing, $\%$ & 64 & 75 \\
\hline Proportion of time with ears pricked, $\%$ & 48 & 64 \\
\hline Proportion of time with whites of eyes visible, $\%$ & 23 & 11.5 \\
\hline Proportion of time spend attending to calf, $\%$ & 74 & 80 \\
\hline Number of other pain indicator behaviors ${ }^{1}$ & 0.4 & 0.3 \\
\hline Number of animals observed eating, no./total no. & $4 / 19^{\mathrm{a}}$ & $0 / 20^{\mathrm{b}}$ \\
\hline
\end{tabular}

(Weary et al., 2006; Broom and Fraser, 2007; Mainau and Manteca, 2011; Barrier et al., 2012), were recorded continuously for 6 to $10 \mathrm{~h}$ of the calving period, after which cows were moved to a cubicle house. The time to placental expulsion was recorded as less than $6 \mathrm{~h}$, between 6 and $12 \mathrm{~h}$, and more than $12 \mathrm{~h}$ after parturition. For at least $3 \mathrm{~d}$ postpartum, cows were monitored for signs of clinical illness, such as metritis, mastitis, and abomasum displacement, and their rectal temperature was recorded daily. At 220 and 305 DIM, the total milk yield was recorded for each cow, as well as the number of inseminations and the pregnancy status. This study was approved by the Welfare and Ethics Committee of the Interdisciplinary Centre of Research in Animal Health of the Lisbon Veterinary Faculty (CIISA-FMV, Lisbon, Portugal).

Data were analyzed using the Mann-Whitney U test for the behavioral data and milk yield, Fisher's exact test for number of animals eating, the 2-sample $t$-test for the rectal temperatures, and the chi-squared test for clinical disease, placental expulsion, and fertility.

Statistical analysis showed that groups were balanced with regard to parity (9 multiparous and 10 primiparous received carprofen) and that no difference existed between groups in number of calvings needing assistance. Behavior results are summarized in Table 1. More animals from the analgesia group were seen eating during the observation period $(P<0.05)$ but no difference was observed in the proportion of time drinking or time spent attending to the calf. No differences were observed between the 2 groups for the other behavioral measures.

Table 2 shows the results of the clinical measures. If calvings were divided into unassisted and assisted, the rectal temperature at $24 \mathrm{~h}$ was lower in the unassisted animals that received analgesia $(P<0.01)$. No difference was observed between the groups in clinical disease incidence during the $3 \mathrm{~d}$ postpartum or delay before placental delivery. At 305 DIM, heifers that were given carprofen had produced more milk than the control group but the total number of cows pregnant at $220 \mathrm{~d}$ of lactation was higher in the control group (Table 3).

More animals from the analgesia group were observed to be eating during the postpartum period (21 vs. $0 \%$ ). It may be that the use of a carprofen reduced pain-associated inappetence and potentially lowered the negative energy balance. This may result in a lower incidence of metabolic problems and higher milk yields (McCrae and Whitaker, 2004).

The rectal temperature at $24 \mathrm{~h}$ postpartum was lower in those that received analgesia but the effect was only significant when the more difficult calving cases were removed from the analysis. Carprofen is known to have antipyretic actions (Fitzpatrick et al., 2004), which may be the direct reason for this difference. Alternatively, the temperatures may be indirectly lower if the use of carprofen reduces the incidence of clinical and subclinical disease by suppressing the cortisol response to pain (Pang et al., 2006). Cortisol is known to cause immunosuppression and, therefore, increase the risk of infection (Fitzpatrick et al., 2004).

This study was designed to test the effects of the analgesics on behavior after calving. The sample was not adequate to provide a definitive test of the effects of treatment on milk yield or reproductive outcomes, so these are presented below for descriptive purposes only. The differences we observed for both outcomes deserve follow-up in larger studies designed to assess these effects.

Table 2. Rectal temperature, time to placental expulsion, and incidence of clinical disease

\begin{tabular}{lcc}
\hline & \multicolumn{2}{c}{ Treatment } \\
\cline { 2 - 3 } Variable & Analgesia & Control \\
\hline Rectal temperature at $24 \mathrm{~h},{ }^{\circ} \mathrm{C}$ & 38.4 & 38.6 \\
Rectal temperature at $48 \mathrm{~h},{ }^{\circ} \mathrm{C}$ & 38.6 & 38.4 \\
Time to placental expulsion, $\mathrm{h}$ & $6-12$ & $6-12$ \\
Incidence of clinical disease $^{\mathrm{l}}$ & 0.31 & 0.35 \\
\hline
\end{tabular}

${ }^{1}$ Clinical diseases include metritis, mastitis, and abomasum displacement. 
Table 3. Total milk yield (mean \pm SE) at 220 and 305 DIM and fertility data at 220 DIM

\begin{tabular}{lcc}
\hline & \multicolumn{2}{c}{ Treatment } \\
\cline { 2 - 3 } Item & Analgesia & Control \\
\hline Cows & 9 & 10 \\
$\mathrm{n}$ & $7,476 \pm 811$ & $7,413 \pm 1,838$ \\
Milk yield at 220 DIM, kg & $11,523 \pm 3,180$ & $11,400 \pm 781$ \\
Milk yield at 305 DIM, kg & 10 & 10 \\
Heifers & $7,142 \pm 818$ & $5,615 \pm 2,057$ \\
$\mathrm{n}$ & $11,210 \pm 3,116^{\mathrm{a}}$ & $8,617 \pm 1,723^{\mathrm{b}}$ \\
Milk yield at 220 DIM, kg & $6^{\mathrm{a}}$ & $11^{\mathrm{b}}$ \\
Milk yield at 305 DIM, kg & 11 & 4 \\
All animals & & \\
No. pregnant at 220 DIM & & \\
No. nonpregnant but inseminated at 220 DIM & & \\
a,b Means within a row with different superscript letters differ $(P<0.05)$. &
\end{tabular}

The milk yield of first-lactation animals at 220 DIM tended to be higher in the analgesia group than the control group and was significantly higher at 305 DIM. A higher DMI postpartum is associated with a steep increase in milk yield, which will result in overall higher production (McCrae and Whitaker, 2004). Several studies have demonstrated that the use of carprofen alleviates pain and reduces inappetence associated with pain (Pang et al. 2006; Stilwell et al., 2008). This may have reduced the negative energy balance that commonly occurs in early lactation, reducing also the possibility of occurrence of subclinical ketosis and other diseases. Another explanation for the higher production in heifers is that carprofen may have reduced the cortisol response to pain and, thus, potentially reduced the levels of clinical and subclinical infectious diseases, such as mastitis.

The number of animals pregnant by $220 \mathrm{~d}$ postpartum was higher in the control group than in the analgesia group (11 vs. 6). Five cows in the control group and 2 in the analgesia group were never inseminated, being listed for culling at the end of lactation. Previous studies with flunixin-meglumine in pigs and cows have had conflicting conclusions regarding its effect on uterine involution and placental delivery (Odensvik and Fredriksson, 1993; Amiridis et al., 2001; Duffield et al., 2009). Further knowledge of the exact mechanism of action of carprofen and more detailed production data would allow a better understanding of this. It may be that because animals within the analgesia group had a higher milk yield, this delayed resumption of ovarian function (Walsh et al., 2007).

The general conclusion drawn from this small study is that a potential role for analgesia use exists in the postparturient cow, but that evidence from further studies is required before a recommendation can be made. Some of the trends in the behavioral, clinical, and production data suggest that analgesic use does have a positive effect on the welfare of postparturient cows and on milk yield from primiparous animals.

\section{ACKNOWLEDGMENTS}

We thank all of the staff at Vale da Lama (Ribatejo, Portugal) for their invaluable help and cooperation.

\section{REFERENCES}

Amiridis, G. S., L. Leontides, E. Tassos, P. Kostoulas, and G. C. Fthenakis. 2001. Flunixin-meglumine accelerates uterine involution and shortens the calving-to-first-oestrus interval in cows with puerperal metritis. J. Vet. Pharmacol. Ther. 24:365-367.

Barrier, A. C., E. Ruelle, M. J. Haskell, and C. M. Dwyer. 2012. Effect of a difficult calving on the vigour of the calf, the onset of maternal behaviour, and some behavioural indicators of pain in the dam. Prev. Vet. Med. 103:248-256.

Broom, D. M., and A. F. Fraser. 2007. Domestic Animal Behaviour and Welfare. 4th ed. Page 438. CABI, Wallingford, UK.

Duffield, T. F., H. Putnam-Dingwell, D. Weary, A. Skidmore, L. Neuder, W. Raphael, S. Millman, N. Newby, and K. E. Leslie. 2009. Effect of flunixin-meglumine treatment following parturition on cow health and milk production. J. Dairy Sci. 92(E. Suppl.):118. (Abstr.)

Fitzpatrick, J. L., A. M. Nolan, P. Lees, and S. A. May. 2004. Inflammation and pain. Pages 1050-1056 in Bovine Medicine. A. H. Andrews, R. W. Blowey, H. Boyd, and R.G. Eddy, ed. Blackwell Science, Oxford, UK.

Huxley, J. N., and H. R. Whay. 2006. Current attitudes of cattle practitioners to pain and the use of analgesics in cattle. Vet. Rec. 159:662-668.

Laven, R., P. Chambers, and K. Stafford. 2012. Using non-steroidal anti-inflammatory drugs around calving: Maximizing comfort, productivity and fertility. Vet. J. 192:8-12.

Mainau, E., and X. Manteca. 2011. Pain and discomfort caused by parturition in cows and sows. Appl. Anim. Behav. Sci. 135:241-251.

McCrae, A. and Whitaker, D. 2004. Veterinary Role in Nutrition and Fertility Management in Dairy Cows. University of Edinburgh Continuing Professional Development (CPD) course, Easter Bush, Sep. 8-9, 2004. University of Edinburgh, UK.

Mee, J. F. 2004. Managing the dairy cow at calving time. Vet. Clin. North Am. Food Anim. Pract. 20:521-546.

Milligan, B. N., T. Duffield, and K. Lissemore. 2004. The utility of ketoprofen for alleviating pain following dehorning in young dairy calves. Can. Vet. J. 45:140-143. 
Odensvik, K., and G. Fredriksson. 1993. The effect of intensive flunixin treatment during the postpartum period in the bovine. Zentralbl. Veterinärmed. A 40:561-568.

Pang. W. Y.. B. Earley, T. Sweeney, and M. A. Crowe. 2006. Effect of carprofen administration during banding or Burdizzo castration of bulls on plasma cortisol, in vitro interferon- $\gamma$ production, acutephase proteins, feed intake, and growth. J. Anim. Sci. 84:351-359.

Stilwell, G., M. S. Lima, and D. M. Broom. 2008. Effects of nonsteroidal anti-inflammatory drugs on long-term pain in calves castrated by use of an external clamping technique following epidural anesthesia. Am. J. Vet. Res. 69:744-750.
Walsh, R. B., J. S. Walton, D. F. Kelton, S. J. LeBlanc, K. E. Leslie, and T. F. Duffield. 2007. The effect of subclinical ketosis in early lactation on reproductive performance of postpartum dairy cows. J. Dairy Sci. 90:2788-2796.

Weary, D. M., L. Niel, F. C. Flower, and D. Fraser. 2006. Identifying and preventing pain in animals. Appl. Anim. Behav. Sci. 100:64-76.

Whay, H. R., D. C. J. Main, L. E. Green, and A. J. F. Webster. 2003. Animal based measures for the assessment of welfare state of dairy cattle, pigs and laying hens: Consensus of expert opinion. Anim. Welf. 12:205-217. 